\section{Synthesis of $2^{\prime}, 3^{\prime}$-Dideoxynucleoside Phosphoesters Using H-Phosphonate Chemistry on Soluble Polymer Support}

\section{Céline Crauste, Christian Périgaud, and} Suzanne Peyrottes*

UMR 5247 CNRS-UM1-UM2, IBMM, Nucleosides \& Phosphorylated Effectors Team, University Montpellier 2, cc1705, place E. Bataillon, 34095 Montpellier, France

suzanne.peyrottes@univ-montp2.fr

Received November 18, 2010

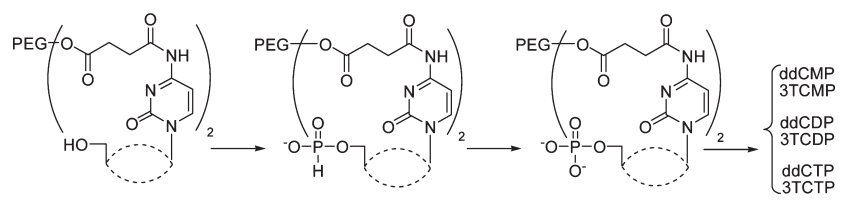

Phosphorylation of $\mathrm{ddC}$ and $3 \mathrm{TC}$ was efficiently performed on soluble poly(ethylene glycol) support. The corresponding $5^{\prime}$-monophosphate derivatives were obtained by oxidation of the support bound $5^{\prime}$-H-phosphonate intermediates. Then, di- and triphosphorylations were carried out using a carbonyldiimidazole activation step followed by nucleophilic substitution with suitable phosphate salts. Trivalent phosphorus chemistry appeared as a good alternative for monophosphate synthesis of acid-sensitive $2^{\prime}, 3^{\prime}$-dideoxynucleosides.

A wide variety of nucleoside analogues, mostly active as their $5^{\prime}$-triphosphate forms, are currently used as antiviral agents. ${ }^{1}$ Despite the importance of such phosphorylated analogues as biological tools, to date no protocol for making nucleoside $5^{\prime}$-triphosphates is universally satisfactory. Indeed, the success of the phosphorylation depends considerably on the nature of the substrate, and several fastidious purification steps cannot be avoided. ${ }^{2}$

To reach reaction completion and to significantly simplify purification procedures, we recently developed an efficient solution-phase process based on the use of a soluble poly(ethylene glycol) (PEG) support, for the synthesis of $5^{\prime}$-mono, di-, and triphosphates of cytidine derivatives. ${ }^{3}$ Thus, the support-bound nucleoside $5^{\prime}$-monophosphates of araC, $\mathrm{dC}$, and $\mathrm{C}$ were obtained using phosphorus oxychloride $\left(\mathrm{POCl}_{3}\right)$ as $\mathrm{P}^{\mathrm{V}}$ phosphorylating reagent, and such intermediates allowed the synthesis of the corresponding di- and triphosphate derivatives following the Hoard phosphorylation method. ${ }^{4}$

(1) De Clercq, E. Rev. Med. Virol. 2009, 19, 287.

(2) Burgess, K.; Cook, D. Chem. Rev. 2000, 100, 2047.

(3) Crauste, C.; Périgaud, C.; Peyrottes, S. J. Org. Chem. 2009, 74, 9165.
SCHEME 1. Attempts toward ddC and 3TC Monophosphorylation Using $\mathbf{P}^{\mathbf{V}}$ Reagent on a Soluble Support

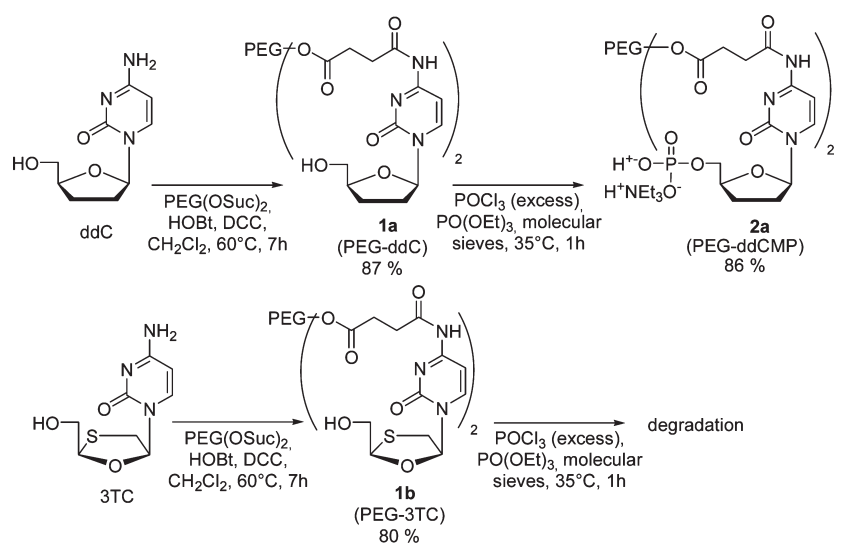

We report herein the extension of this methodology for acid-sensitive analogues such as $2^{\prime}, 3^{\prime}$-dideoxynucleosides. Indeed, 1 - $\left(2^{\prime}, 3^{\prime}\right.$-dideoxy- $\beta$-D-ribofuranosyl $)$-cytosine $(\mathrm{ddC})^{5}$ and $1-\left(2^{\prime}, 3^{\prime}\right.$-dideoxy- $3^{\prime}$-thia- $\beta$-L-ribofuranosyl $)$-cytosine $(3 \mathrm{TC})^{6}$ are commonly used as antiviral nucleoside analogues, ${ }^{1}$ and easy access to their corresponding phosphorylated forms is greatly needed. In a preliminary set of experiments, previously described conditions ${ }^{3}\left(\mathrm{P}^{\mathrm{V}}\right.$ reagent) were applied to PEG-ddC (1a) and PEG-3TC (1b) (Scheme 1). Briefly, the anchoring of both nucleosides onto the succinylate PEG support ${ }^{7}$ was carried out using DCC/HOBt as coupling agents, ${ }^{8}$ and then monophosphorylation was performed in triethylphosphate at $35-40{ }^{\circ} \mathrm{C}$ (due to the low solubility of PEG-supported substrates $\mathbf{1 a}$ and $\mathbf{1 b}$ at $0{ }^{\circ} \mathrm{C}$ ), and in presence of 30 equiv of $\mathrm{POCl}_{3}$. Unfortunately, as a result of acidic reaction conditions, cleavage of the glycosidic bond was observed for both derivatives, and the use of lower amounts of $\mathrm{POCl}_{3}$ led to decreased phosphorylation ratio (estimated by ${ }^{1} \mathrm{H}$ NMR analysis).

To avoid this side reaction, proton sponge ${ }^{9}$ or activated molecular sieves ${ }^{10}$ were added to the reaction mixture. In the case of $\mathrm{ddC}$, the presence of activated molecular sieves allowed the formation of PEG-ddCMP (2a) and only 10\% glycosidic cleavage was observed (Scheme 1). However, these conditions were not appropriate for the 3TC derivative. We hypothesized that the sulfur atom participates to the stabilization of the carbocation species generated during the cleavage of the glycosidic bond, thus increasing chemical instability of PEG-3TC (1b). Consequently, a new synthetic pathway involving $\mathrm{P}^{\mathrm{III}}$ chemistry was explored to perform

(4) Hoard, D. E.; Ott, D. G. J. Am. Chem. Soc. 1965, 87, 1785.

(5) Mitsuya, H.; Broder, S. Proc. Natl. Acad. Sci. U.S.A. 1986, 83, 1911.

(6) Soudeyns, H.; Yao, X. J.; Gao, Q.; Belleau, B.; Kraus, J. L.; Nghe, N. B.; Spira, B.; Wainberg, M. A. Antimicrob. Agents Chemother. 1991, 35, 1386.

(7) Denapoli, L.; Messere, A.; Montesarchio, D.; Piccialli, G.; Santacroce, C.; Bonora, G. M. Nucleosides Nucleotides 1993, 12, 21.

(8) Guo, Z. W.; Gallo, J. M. J. Org. Chem. 1999, 64, 8319

(9) Kovacs, T.; Otvos, L. Tetrahedron Lett. 1988, 29, 4525.

(10) Matulic-Adamic, J.; Beigelman, L. Patent WO/1993/023416, US, 1993 
SCHEME 2. Monophosphorylation of ddC Using $\mathrm{P}^{\mathrm{III}}$ Reagent and Oxidation with tert-Butyl Hydroperoxide on Soluble Support

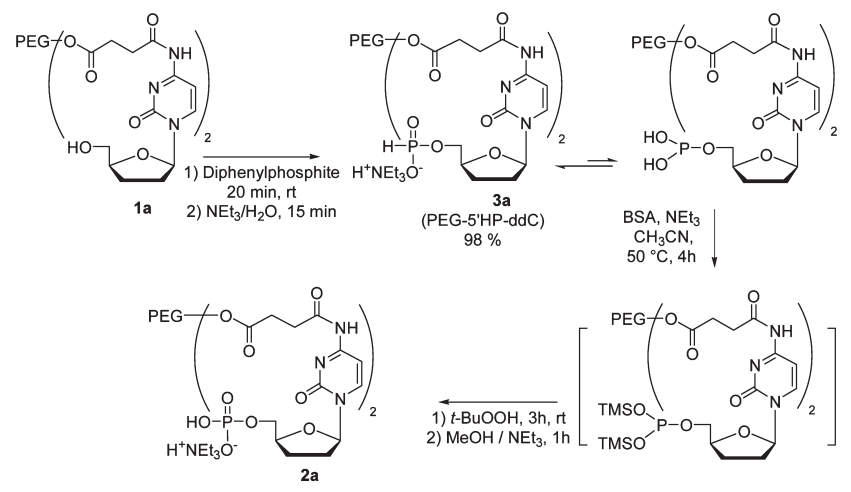

the $5^{\prime}$-monophosphorylation of acid sensitive $2^{\prime}, 3^{\prime}$-dideoxynucleosides on soluble support.

Phosphate monoesters have frequently been synthesized from H-phosphonate diester or phosphite triester intermediates, after subsequent oxidation and removal of the phosphate protecting group. ${ }^{11}$ However, we aimed at developing a rapid and efficient synthetic pathway including the lowest number of steps possible. Thereby, we envisaged the direct oxidation of $5^{\prime}-\mathrm{H}$-phosphonate monoester nucleosides to their corresponding $5^{\prime}$-monophosphates. This reaction has been less often reported in view of the lower reactivity of $\mathrm{H}$-phosphonate monoesters toward oxidation, compared to $\mathrm{H}$-phosphonate diesters or phosphite triesters. The H-phosphonate monoester has to be temporarily convert to its highly reactive phosphite form using silylated protecting groups. ${ }^{12-14}$ After mild oxidation by elemental iodine, ${ }^{15,16}$ tertbutyl hydroperoxide, ${ }^{17}$ or (camphorsulfonyl)oxazirine, ${ }^{18}$ a one-pot deprotection step is performed in basic conditions to release the monophosphate function. Thus, phosphitylation was carried out on PEG support using a large excess of diphenylphosphite ${ }^{19}$ in pyridine in order to achieve reaction completion (Scheme 2).

A quantitative conversion was estimated by comparing ${ }^{1} \mathrm{H}$ NMR integration of both signals of the $\mathrm{H}_{6}$ from the nucleobase and of the characteristic signal of the $\mathrm{H}$-phosphonate proton (Figure 1, panels A and B). PEG-ddC 5'-HP (3a) and PEG-3TC 5'-HP (3b) were isolated in $98 \%$ and $88 \%$ yields, respectively, after extraction and precipitation in cold diethyl ether. Among the reagents already described to perform the phosphite oxidation, ${ }^{15-18}$ we first tested easily available silylating and oxidizing reagents such as trimethylsilyl chloride (TMSCl), $N, O$-bis(trimethylsilyl) acetamide (BSA), and

(11) Stawinski, J. In Handbook of Organophosphorus Chemistry; Engel, R., Ed.; Marcel Dekker, Inc.: New York, 1992; p 377.

(12) Hata, T.; Sekine, M. Tetrahedron Lett. 1974, 3943.

(13) Sekine, M.; Yamagata, H.; Hata, T. Tetrahedron Lett. 1979, 375

(14) Zlatev, I.; Lavergne, T.; Debart, F.; Vasseur, J. J.; Manoharan, M.; Morvan, F. Org. Lett. 2010, 12, 2190.

(15) Garegg, J.; Regberg, T.; Stawinski, J.; Stromberg, R. Nucleosides Nucleotides 1987, 6, 429.

(16) Garegg, P. J.; Regberg, T.; Stawinski, J.; Stromberg, R. J. Chem. Soc., Perkin Trans. 1 1987, 1269.

(17) Dreef, C. E.; Vandermarel, G. A.; Vanboom, J. H. J. Royal Netherlands Chem. Soc. 1987, 106, 512.

(18) Wada, T.; Mochizuki, A.; Sato, Y.; Sekine, M. Tetrahedron Lett. 1998, 39, 7123

(19) Jankowska, J.; Sobkowski, M.; Stawinski, J.; Kraszewski, A. Tetrahedron Lett. 1994, 35, 3355.

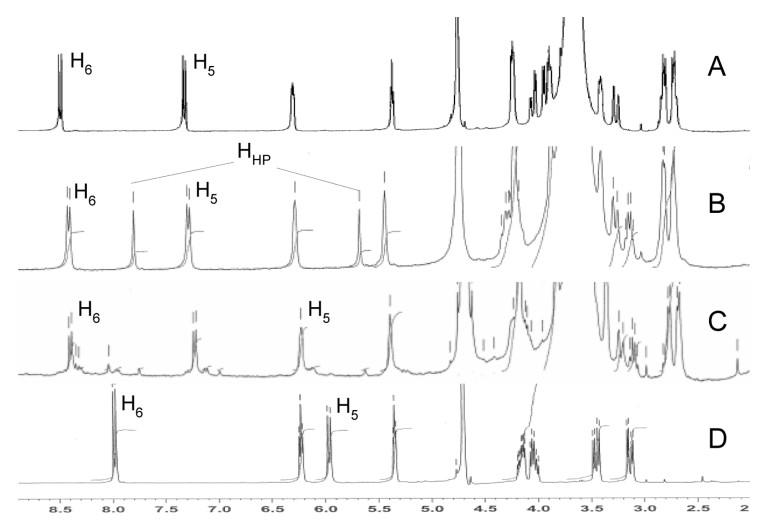

FIGURE 1. ${ }^{1} \mathrm{H}$ NMR spectra of PEG-3TC (A), PEG-3TC 5 -HP (B), PEG-3TCMP (C), and 3TCMP (D).

tert-butyl hydroperoxide $(t-\mathrm{BuOOH})$ or $\mathrm{I}_{2} / \mathrm{H}_{2} \mathrm{O} /$ Pyridine mixture. The use of an excess of BSA (40 equiv) at $50{ }^{\circ} \mathrm{C}$ and the addition of triethylamine were essential for an efficient conversion of the $\mathrm{H}$-phosphonate derivative into the corresponding silyl phosphite intermediate. $t$-BuOOH was also used in large excess (100 equiv) to overcome the formation of the less reactive $t$-BuOOTMS in the presence of remaining BSA. Thus, PEG-ddCMP (2a) was finally obtained albeit contaminated with $16 \%$ (estimated by integration of nucleobase signals in ${ }^{1} \mathrm{H}$ NMR analysis) of starting material (PEG-ddC 5'-HP, 3a).

Applied to PEG-3TC-5'HP (3b), this last protocol led to the formation of secondary products (probably associated with sulfur oxidation), and a low conversion into the $5^{\prime}$-monophosphate (2b) was observed. Even so, oxidation with peroxide had already been reported for a 3TC derivative $^{20}$ without mention of side reaction. In view of the particular reactivity of 3TC, the use of an iodine solution in a mixture of pyridine and water (ratio 98/2, v/v) ${ }^{15,16}$ resulted in complete disappearance of the starting $5^{\prime}-\mathrm{H}$ phosphonate (3b, Figure 1C). However, ${ }^{31} \mathrm{P}$ NMR analysis revealed the presence of a dinucleoside $\left(\mathrm{P}, \mathrm{P}^{\prime}\right)$ pyrophosphate entity (10) in addition to the desired $5^{\prime}$-monophosphate compound (2b) (scheme 3, A).

The structure of this byproduct was proposed on the basis of the presence of an extra phosphate signal at $-11 \mathrm{ppm}$, characteristic of $5^{\prime}, 5^{\prime}$-pyrophosphate dinucleosides and further spectral analysis after cleavage of the compound from the support (see Supporting Information). This compound (10) may result from a nucleophilic attack of the monophosphate species $(\mathbf{2} \mathbf{a}, \mathbf{b})$ on the activated pyridinium intermediate (4) generated in situ during the oxidation. Thus, we hypothesized that by increasing the amount of water in the reaction mixture, the hydrolysis of the pyridinium intermediate would be favored compared to the nucleophilic attack of the 5'-monophosphate $(\mathbf{2 a}, \mathbf{b})$ already formed (Scheme 3B). After few attempts, the pyridine/water ratio of $80 / 20$ was selected to minimize the formation of the dinucleoside $\left(\mathrm{P}, \mathrm{P}^{\prime}\right)$ pyrophosphate of $\mathrm{ddC}$ (detected as traces in ${ }^{31} \mathrm{P}$ NMR analysis). After extraction and precipitation, PEG-ddCMP 2a was obtained in $86 \%$ yield. By testing this last protocol for the synthesis of PEG-3TCMP $\mathbf{2 b}$, a

(20) Erion, M. D.; Reddy, K. R.; Boyer, S. H.; Matelich, M. C.; GornezGaleno, J.; Lemus, R. H.; Ugarkar, B. G.; Colby, T. J.; Schanzer, J.; van Poelje, P. D. J. Am. Chem. Soc. 2004, 126, 5154. 
SCHEME 3. Attempts toward ddC and 3TC Monophosphorylation Using $\mathrm{P}^{\mathrm{III}}$ Reagent and Oxidation with Iodine/Pyridine/Water Mixture on Soluble Support

A.

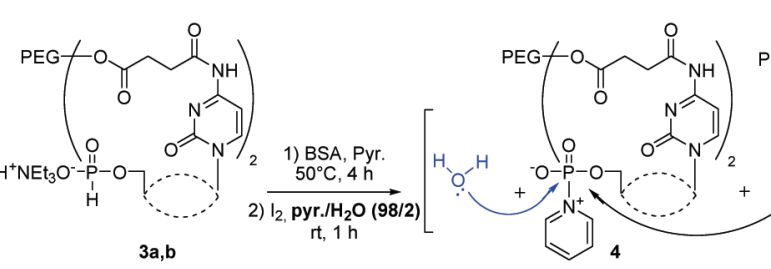

$\mathrm{rt}, 1 \mathrm{~h}$

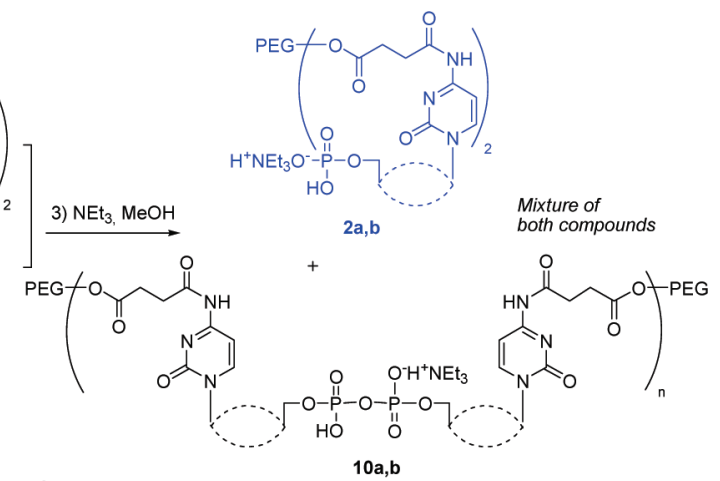

B.
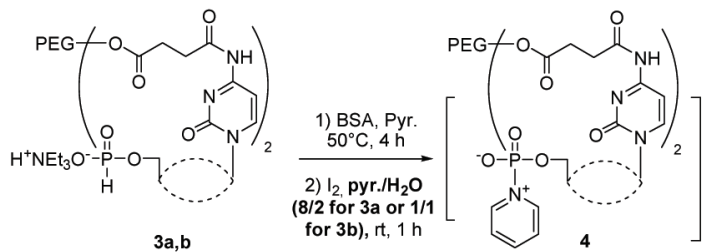

3) $\mathrm{NEt}_{3}, \mathrm{MeOH}$

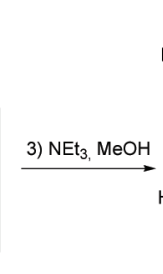

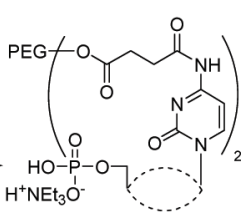

2a (PEG-ddCMP), $84 \%$ 2b (PEG-3TCMP), quantitative

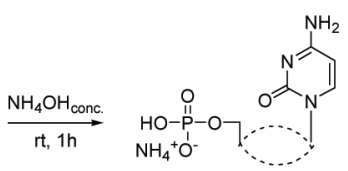
$5 \mathbf{a}($ ddCMP), $79 \%$ HPLC purity $=93 \%$
5 b (3TCMP), $64 \%$ HPLC purity $=99 \%$ pyridine/water ratio of $50 / 50$ proved to be optimum to minimize the formation of the 3TC dimer while keeping high conversion. Recovery of ddCMP $\mathbf{5 a}$ and 3TCMP 5b was performed after cleavage of the succinyl linker using concentrated ammonia. Filtration of the crude product through a reverse phase RP18 column was performed to eliminate PEG residues, and succinamide (the byproduct generated from the cleavage of the succinate linker) was removed by dialysis. The remaining traces of the starting $\mathrm{H}$-phosphonate derivative as well as the dinucleoside $\left(\mathrm{P}, \mathrm{P}^{\prime}\right)$ pyrophosphate were also eliminated during this simple and final purification step and the required nucleoside monophosphates $(\mathbf{5 a}, \mathbf{b})$ were obtained in good yields and high HPLC ${ }^{21}$ purities.

Further phosphorylation steps were performed as previously reported. ${ }^{3}$ Briefly, the supported $5^{\prime}$-monophosphate nucleoside is first activated by 1,1-carbonyldiimidazole (CDI), and subsequent condensation of the $5^{\prime}$-phosphoroimidazolidate intermediate with inorganic phosphate or pyrophosphate is carried out (Scheme 4). Completion of these reactions can easily monitored by ${ }^{31} \mathrm{P}$ NMR (formation and then the disappearance of the activated imidazolidate phosphorus signal). PEG-ddCDP (6a) and PEG-ddCTP (7a), PEG-3TCDP (6b) and PEG-3TCTP (7b) were obtained as described in Scheme 4 after filtration on reverse phase RPC18 column in order to eliminate residual phosphorus salts.

Finally, treatment of supported di- and triphosphates with concentrated aqueous ammonia, purification on reverse phase column, and dialysis yielded ddCDP, ddCTP, 3TCDP and 3TCTP in good to modest yields and with good HPLC purities.

The synthesis of $5^{\prime}$-mono, di-, and triphosphates of ddC and 3TC (as models of acid sensitive nucleoside analogues) was achieved using a soluble phase process based on a PEG support. In view of the chemical stability of $2^{\prime}, 3^{\prime}$-dideoxynucleosides, a useful and efficient alternative method involv-

(21) Crauste, C.; Lefebvre, I.; Hovaneissian, M.; Puy, J. Y.; Roy, B.; Peyrottes, S.; Cohen, S.; Guitton, J.; Dumontet, C.; Perigaud, C. J. Chromatogr. B 2009, 877, 1417.
SCHEME 4. Synthesis of $\mathrm{ddC}$ and 3TC Di- and Triphosphates on Soluble Support

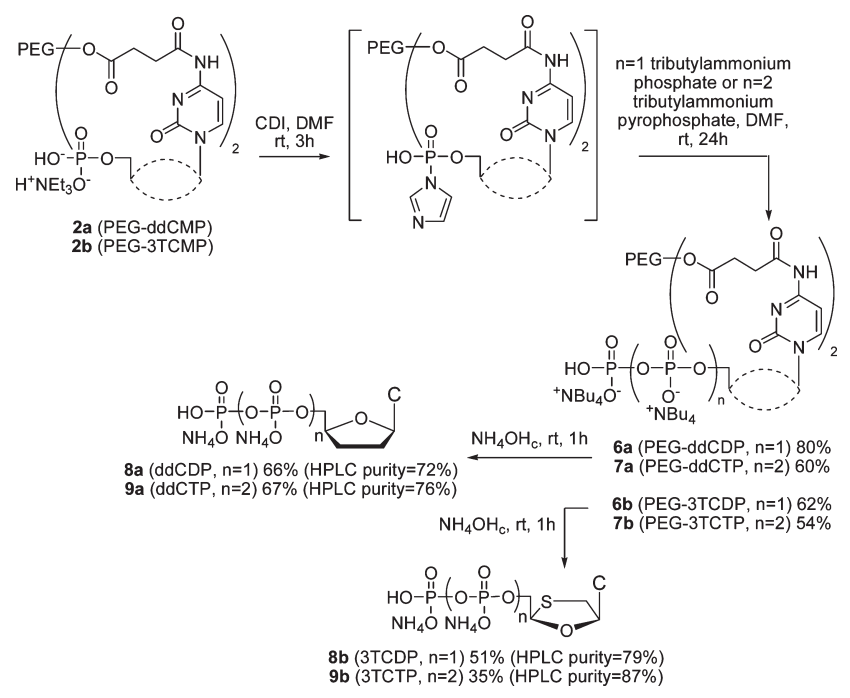

ing H-phosphonate supported oxidation has been developed. In addition to the access to the desired 3TC and ddC phosphoesters, the usefulness of this approach based on $\mathrm{P}^{\mathrm{III}}$ chemistry may open the way to the synthesis of various nucleotide analogues on support.

\section{Experimental Section}

General Procedure for H-Phosphonate Synthesis. To a solution of support-bound nucleoside (1 equiv) in anhydrous pyridine $(3.75 \mathrm{~mL})$ was added diphenylphosphite $(1.60 \mathrm{mmol}, 30$ equiv). The solution was stirred at room temperature for $20 \mathrm{~min}$, and then a triethylamine/water solution $(1.25 \mathrm{~mL}, 1 / 1, \mathrm{v} / \mathrm{v})$ was added. After $15 \mathrm{~min}$ the mixture was concentrated under reduced pressure. The residue was dissolved in dichloromethane $(30 \mathrm{~mL})$, and the organic layer washed with aqueous $\mathrm{NaHCO}_{3}$ $(5 \%$ solution, $\mathrm{w} / \mathrm{v}, 20 \mathrm{~mL})$. The aqueous layer was extracted several times by dichloromethane $(30 \mathrm{~mL})$. The organic layers were combined and evaporated under reduced pressure. The 
PEG-supported nucleoside H-phosphonate was precipitated from a dichloromethane solution by addition of an excess volume of cold diethyl ether $(25 \mathrm{~mL})$. The precipitate was filtered and washed with diethyl ether. The final product was recrystallized from ethyl alcohol absolute $(5 \mathrm{~mL})$ and dried under vacuum over $\mathrm{KOH}$ pellets.

Poly(ethylene glycol $) 4000 \mathrm{Bis}\left[4-\mathrm{N}-\left(1-\left(2^{\prime}, 3^{\prime}\right.\right.\right.$-dideoxy-5'-hydrogeno-phosphonyl- $\beta$-D-ribofuranosyl)-cytosyl) succinate], Triethylammonium Salt (3a). PEG-ddC $\mathbf{1 b}(0.25 \mathrm{~g}, 0.05 \mathrm{mmol})$ was treated as previously described and afforded compound $\mathbf{3 a}$ as a white solid $(0.23 \mathrm{~g}, 86 \%) . \delta_{\mathrm{H}}\left(\mathrm{D}_{2} \mathrm{O}, 300 \mathrm{MHz}\right) 8.34\left(\mathrm{~d}, J_{6-5}=\right.$ $\left.7.4 \mathrm{~Hz}, 1 \mathrm{H}, \mathrm{H}_{6}\right), 7.26\left(\mathrm{~d}, J_{5-6}=7.4 \mathrm{~Hz}, 1 \mathrm{H}, \mathrm{H}_{5}\right), 6.67\left(\mathrm{~d}, J_{\mathrm{H}-\mathrm{P}}=\right.$ $\left.637.2 \mathrm{~Hz}, 1 \mathrm{H}, \mathrm{H}_{\mathrm{HP}}\right), 5.99\left(\mathrm{~m}, 1 \mathrm{H}, \mathrm{H}_{1^{\prime}}\right), 4.32\left(\mathrm{~m}, 1 \mathrm{H}, \mathrm{H}_{4^{\prime}}\right)$, 4.18-4.09 (m, 3H, $\left.\left(\mathrm{OCH}_{2} \alpha\right)_{\mathrm{PEG}} \mathrm{H}_{5^{\prime} \mathrm{a}}\right), 3.94\left(\mathrm{~m}, 1 \mathrm{H}, \mathrm{H}_{5^{\prime} \mathrm{b}}\right)$, $3.83-3.36\left(\mathrm{~m},\left(\mathrm{OCH}_{2}\right)_{\mathrm{PEG}}\right), 3.09\left(\mathrm{q}, J=7.2 \mathrm{~Hz}, 6 \mathrm{H},\left(\mathrm{CH}_{3^{-}}\right.\right.$ $\left.\left.\mathrm{CH}_{2}\right)_{3} \mathrm{NH}\right), 2.82-2.66\left(\mathrm{~m}, 4 \mathrm{H}, \mathrm{CH}_{2 \text { succ }}\right), 2.45\left(\mathrm{~m}, 1 \mathrm{H}, \mathrm{H}_{2^{\prime} \mathrm{a}}\right)$, $2.08-1.97\left(\mathrm{~m}, 2 \mathrm{H}, \mathrm{H}_{2^{\prime} \mathrm{b}} \mathrm{H}_{3^{\prime} \mathrm{a}}\right), 1.78\left(\mathrm{~m}, 1 \mathrm{H}, \mathrm{H}_{3^{\prime} \mathrm{b}}\right), 1.17(\mathrm{t}, J=7.2$ $\left.\mathrm{Hz}, 9 \mathrm{H},\left(\mathrm{CH}_{3} \mathrm{CH}_{2}\right)_{3} \mathrm{NH}\right) ; \delta_{\mathrm{C}}\left(\mathrm{D}_{2} \mathrm{O}, 75 \mathrm{MHz}\right) 174.5,174.4(2 \mathrm{~s}$, $\left.\mathrm{C}=\mathrm{O}_{\text {succ }}\right), 162.3\left(\mathrm{~s}, \mathrm{C}_{4}\right), 156.9\left(\mathrm{~s}, \mathrm{C}_{2}\right), 146.8\left(\mathrm{~s}, \mathrm{C}_{6}\right), 97.6\left(\mathrm{~s}, \mathrm{C}_{5}\right)$, $88.2\left(\mathrm{~s}, \mathrm{C}_{1^{\prime}}\right), 86.6\left(\mathrm{~d}, J_{\mathrm{C}^{\prime}-\mathrm{P}}=7.6 \mathrm{~Hz}, \mathrm{C}_{4^{\prime}}\right), 69.6\left(\mathrm{~s},\left(\mathrm{OCH}_{2}\right)_{\mathrm{PEG}}\right)$, $68.4\left(\mathrm{~s},\left(\mathrm{OCH}_{2} \beta\right)_{\mathrm{PEG}}\right), 64.1\left(\mathrm{~s},\left(\mathrm{OCH}_{2} \alpha\right)_{\mathrm{PEG}}\right), 63.9\left(\mathrm{~d}, J_{\mathrm{C}^{\prime}-\mathrm{P}}=\right.$ $\left.3.9 \mathrm{~Hz}, \mathrm{C}_{5^{\prime}}\right), 46.6\left(\mathrm{~s},\left(\mathrm{CH}_{3} \mathrm{CH}_{2}\right)_{3} \mathrm{NH}\right), 32.5\left(\mathrm{~s}, \mathrm{C}_{2^{\prime}}\right), 31.5,28.5(2 \mathrm{~s}$, $\left.\mathrm{CH}_{2 \text { succ }}\right), 24.1\left(\mathrm{~s}, \mathrm{C}_{3^{\prime}}\right), 8.2\left(\mathrm{~s},\left(\mathrm{CH}_{3} \mathrm{CH}_{2}\right)_{3} \mathrm{NH}\right) ; \delta_{\mathrm{P}}\left(\mathrm{D}_{2} \mathrm{O}, 121\right.$ $\mathrm{MHz}) 6.53$ (s).

Poly(ethylene glycol $) 4000$ Bis[4- $N$-(1- $\left(2^{\prime}, 3^{\prime}\right.$-dideoxy-5'-hydrogeno-phosphonyl-3' $\boldsymbol{3}^{\prime}$-thia- $\boldsymbol{\beta}$-L-ribofuranosyl)-cytosyl) succinate], Triethylammonium Salt (3b). PEG-3TC 1b (0.30 g, $0.06 \mathrm{mmol})$ was treated as previously described and afforded compound $\mathbf{3 b}$ as a white solid $(0.28 \mathrm{~g}, 87 \%) . \delta_{\mathrm{H}}\left(\mathrm{D}_{2} \mathrm{O}, 300 \mathrm{MHz}\right) 8.39(\mathrm{~d}$, $\left.J_{6-5}=7.4 \mathrm{~Hz}, 1 \mathrm{H}, \mathrm{H}_{6}\right), 7.26\left(\mathrm{~d}, J_{5-6}=7.4 \mathrm{~Hz}, 1 \mathrm{H}, \mathrm{H}_{5}\right), 6.71(\mathrm{~d}$, $\left.J_{\mathrm{H}-\mathrm{P}}=641.9 \mathrm{~Hz}, 1 \mathrm{H}, \mathrm{H}_{\mathrm{HP}}\right), 6.25\left(\mathrm{~s}, 1 \mathrm{H}, \mathrm{H}_{1^{\prime}}\right), 5.40\left(\mathrm{~s}, 1 \mathrm{H}, \mathrm{H}_{4^{\prime}}\right)$, 4.29-4.13 (m, 4H, $\left.\left(\mathrm{OCH}_{2} \alpha\right)_{\text {PEG }} \mathrm{H}_{5^{\prime} \mathrm{a}} \mathrm{H}_{5^{\prime} \mathrm{b}}\right), 3.85-3.36(\mathrm{~m}$, $\left.\left.\mathrm{OCH}_{2}\right)_{\mathrm{PEG}} \mathrm{H}_{2^{\prime} \mathrm{a}}\right), 3.22\left(\mathrm{~m}, 1 \mathrm{H}, \mathrm{H}_{2^{\prime} \mathrm{b}}\right), 3.10(\mathrm{q}, J=7.2 \mathrm{~Hz}, 6 \mathrm{H}$, $\left.\left(\mathrm{CH}_{3} \mathrm{CH}_{2}\right)_{3} \mathrm{NH}\right), 2.79-2.65\left(\mathrm{~m}, 4 \mathrm{H}, \mathrm{CH}_{2 \text { succ }}\right), 1.18(\mathrm{t}, J=7.2$ $\left.\mathrm{Hz}, 9 \mathrm{H},\left(\mathrm{CH}_{3} \mathrm{CH}_{2}\right)_{3} \mathrm{NH}\right) ; \delta_{\mathrm{C}}\left(\mathrm{D}_{2} \mathrm{O}, 100 \mathrm{MHz}\right) 174.6,174.5(2 \mathrm{~s}$, $\left.\mathrm{C}=\mathrm{O}_{\text {succ }}\right), 162.6\left(\mathrm{~s}, \mathrm{C}_{4}\right), 156.6\left(\mathrm{~s}, \mathrm{C}_{2}\right), 146.1\left(\mathrm{~s}, \mathrm{C}_{6}\right), 97.6\left(\mathrm{~s}, \mathrm{C}_{5}\right)$, $88.0\left(\mathrm{~s}, \mathrm{C}_{1^{\prime}}\right), 86.1\left(\mathrm{~s}, \mathrm{C}_{4^{\prime}}\right), 69.6\left(\mathrm{~s},\left(\mathrm{OCH}_{2}\right)_{\mathrm{PEG}}\right), 68.4(\mathrm{~s}$, $\left.\left(\mathrm{OCH}_{2} \beta\right)_{\mathrm{PEG}}\right), 64.2\left(\mathrm{~s},\left(\mathrm{OCH}_{2} \alpha\right)_{\mathrm{PEG}}\right), 63.5\left(\mathrm{~s}, \mathrm{C}_{5^{\prime}}\right), 46.5(\mathrm{~s}$, $\left.\left(\mathrm{CH}_{3} \mathrm{CH}_{2}\right)_{3} \mathrm{NH}\right), 37.8\left(\mathrm{~s}, \mathrm{C}_{2}\right), 31.6,28.5\left(2 \mathrm{~s}, \mathrm{CH}_{2 \text { succ }}\right), 8.1(\mathrm{~s}$, $\left.\left(\mathrm{CH}_{3} \mathrm{CH}_{2}\right)_{3} \mathrm{NH}\right) ; \delta_{\mathrm{P}}\left(\mathrm{D}_{2} \mathrm{O}, 121 \mathrm{MHz}\right) 6.35(\mathrm{~s})$.

Procedures for H-Phosphonate Oxidation. Poly(ethylene glycol)4000 Bis $\left[4-N\right.$-(1-( $2^{\prime}, 3^{\prime}$-dideoxy-5' $-O$-monophosphoryl- $\beta$-D-ribofuranosyl)-cytosyl) succinate], Triethylammonium Salt (2a). To a solution of PEG-ddC 5'-HP $3 \mathbf{a}(0.10 \mathrm{~g}, 0.02 \mathrm{mmol})$ in anhydrous acetonitrile $(1.50 \mathrm{~mL})$ were added $N, O$-bis(trimethylsilyl) acetamide $(0.20 \mathrm{~mL}$, $0.81 \mathrm{mmol})$ and anhydrous triethylamine $(0.06 \mathrm{~mL}, 0.40 \mathrm{mmol})$. The solution was stirred at $50{ }^{\circ} \mathrm{C}$ during $4 \mathrm{~h}$, the mixture was cooled to $0{ }^{\circ} \mathrm{C}$, and oxidation was carried out by addition of tert-butyl hydroperoxide (5-6 M solution in decane, $2.00 \mathrm{mmol}, 0.36 \mathrm{~mL}$ ). The mixture was stirred for $3 \mathrm{~h}$ at room temperature, then treated by an excess amount of $\mathrm{MeOH}$ and $\mathrm{NEt}_{3}(1 / 1, \mathrm{v} / \mathrm{v}, 0.50 \mathrm{~mL})$, and stirring was pursued for $1 \mathrm{~h}$. The solvents were evaporated under reduced pressure, and the residue was dissolved in dichloromethane $(10 \mathrm{~mL})$. The organic layer was washed with aqueous sodium bicarbonate solution $(5 \%, \mathrm{w} / \mathrm{v}, 7 \mathrm{~mL})$, and the aqueous layer was extracted several times by dichloromethane $(10 \mathrm{~mL})$. The organic layers were combined and evaporated under reduced pressure. The support-bound nucleosid- $5^{\prime}$-yl phosphate was precipitated from a dichloromethane solution by addition of an excess volume of cold diethyl ether $(100 \mathrm{~mL})$. The precipitate was filtered and washed with diethyl ether. Compound 2a (containing 16\% of remaining starting material 3a) was obtained as a white solid $(0.09 \mathrm{~g}, 89 \%) . \delta_{\mathrm{H}}\left(\mathrm{D}_{2} \mathrm{O}\right.$, $300 \mathrm{MHz}) 8.49\left(\mathrm{~d}, J_{6-5}=7.5 \mathrm{~Hz}, 1 \mathrm{H}, \mathrm{H}_{6}\right), 7.13\left(\mathrm{~d}, J_{5-6}=7.3 \mathrm{~Hz}\right.$, $\left.1 \mathrm{H}, \mathrm{H}_{5}\right), 5.98\left(\mathrm{~d}, J_{1^{\prime}-2^{\prime}}=5.1 \mathrm{~Hz}, 1 \mathrm{H}, \mathrm{H}_{1^{\prime}}\right), 4.35\left(\mathrm{~m}, 1 \mathrm{H}, \mathrm{H}_{4}{ }^{\prime}\right), 4.19$ $\left(\mathrm{m}, 3 \mathrm{H},\left(\mathrm{OCH}_{2} \mathrm{\alpha}\right)_{\mathrm{PEG}} \mathrm{H}_{5^{\prime} \mathrm{a}}\right), 3.98-3.92\left(\mathrm{~m}, 1 \mathrm{H}, \mathrm{H}_{5^{\prime} \mathrm{b}}\right), 3.85-3.36(\mathrm{~m}$, $\left.\left(\mathrm{OCH}_{2}\right)_{\mathrm{PEG}}\right), 3.10\left(\mathrm{q}, J=7.2 \mathrm{~Hz}, 6 \mathrm{H},\left(\mathrm{CH}_{3} \mathrm{CH}_{2}\right)_{3} \mathrm{NH}\right), 2.79-2.68$ (m, 4H, $\left.\mathrm{CH}_{2 \text { succ }}\right), 2.46\left(\mathrm{~m}, 1 \mathrm{H}, \mathrm{H}_{2^{\prime}} \mathrm{a}\right), 2.08\left(\mathrm{~m}, 1 \mathrm{H}, \mathrm{H}_{2^{\prime} \mathrm{b}}\right), 1.97(\mathrm{~m}$, $\left.1 \mathrm{H}, \mathrm{H}_{3^{\prime} \mathrm{a}}\right), 1.83\left(\mathrm{~m}, 1 \mathrm{H}, \mathrm{H}_{3^{\prime} \mathrm{b}}\right), 1.18\left(\mathrm{t}, J=7.2 \mathrm{~Hz}, 9 \mathrm{H},\left(\mathrm{CH}_{3^{-}}\right.\right.$ $\left.\left.\mathrm{CH}_{2}\right)_{3} \mathrm{NH}\right) ; \delta_{\mathrm{C}}\left(\mathrm{D}_{2} \mathrm{O}, 100 \mathrm{MHz}\right) 174.5,174.5\left(2 \mathrm{~s}, \mathrm{C}=\mathrm{O}_{\text {succ }}\right), 161.9(\mathrm{~s}$, $\left.\mathrm{C}_{4}\right), 156.0\left(\mathrm{~s}, \mathrm{C}_{2}\right), 146.3\left(\mathrm{~s}, \mathrm{C}_{6}\right), 97.4\left(\mathrm{~s}, \mathrm{C}_{5}\right), 88.3\left(\mathrm{~s}, \mathrm{C}_{1^{\prime}}\right), 81.8(\mathrm{~d}$, $\left.J_{\mathrm{C}^{\prime}-\mathrm{P}}=9.0 \mathrm{~Hz}, \mathrm{C}_{4^{\prime}}\right), 69.5\left(\mathrm{~s},\left(\mathrm{OCH}_{2}\right)_{\mathrm{PEG}}\right), 68.4\left(\mathrm{~s},\left(\mathrm{OCH}_{2} \beta\right)_{\mathrm{PEG}}\right)$, $65.2\left(\mathrm{~s}, \mathrm{C}_{5^{\prime}}\right), 64.1\left(\mathrm{~s},\left(\mathrm{OCH}_{2} \mathrm{\alpha}\right)_{\mathrm{PEG}}\right), 46.6\left(\mathrm{~s},\left(\mathrm{CH}_{3} \mathrm{CH}_{2}\right)_{3} \mathrm{NH}\right), 32.6(\mathrm{~s}$, $\left.\mathrm{C}_{2^{\prime}}\right), 31.5,28.4\left(\mathrm{~s}, \mathrm{CH}_{2 \text { succ }}\right), 23.8\left(\mathrm{~s}, \mathrm{C}_{3^{\prime}}\right), 8.2\left(\mathrm{~s},\left(\mathrm{CH}_{3} \mathrm{CH}_{2}\right)_{3} \mathrm{NH}\right) ; \delta_{\mathrm{P}}$ $\left(\mathrm{D}_{2} \mathrm{O}, 121 \mathrm{MHz}\right) 0.37(\mathrm{~s})$.

Poly(ethylene glycol $) 4000 \mathrm{Bis}\left[4-\mathrm{N}-\left(1-\left(2^{\prime}, 3^{\prime}\right.\right.\right.$-dideoxy $-5^{\prime}-O$ mono phosphoryl-3'-thia- $\beta$-L-ribofuranosyl)-cytosyl) succinate], Triethylammonium Salt (2b). To a solution of PEG-3TC $5^{\prime}$-HP 3b $(0.15 \mathrm{~g}, 0.03 \mathrm{mmol})$ in anhydrous pyridine $(2.50 \mathrm{~mL})$ was added $N, O$-bis(trimethyl silyl)acetamide $(0.30 \mathrm{~mL}, 1.21$ mmol). The solution was stirred at $50{ }^{\circ} \mathrm{C}$ for $4 \mathrm{~h}$, the mixture was cooled to $0{ }^{\circ} \mathrm{C}$, and then oxidation was carried out by addition of an iodine solution $(200 \mathrm{mM}, 75 \mathrm{mg}, 0.30 \mathrm{mmol})$ in pyridine-water $(56 / 44, \mathrm{v} / \mathrm{v}, 1.50 \mathrm{~mL})$ at room temperature. The mixture was stirred for $1 \mathrm{~h}$, treated by an excess amount of $\mathrm{MeOH}$ and $\mathrm{NEt}_{3}(1 / 1, \mathrm{v} / \mathrm{v}, 1.50 \mathrm{~mL})$, and stirring was pursued for $1 \mathrm{~h}$. The solvents were evaporated under reduced pressure, and the residue was dissolved in dichloromethane $(15 \mathrm{~mL})$. The organic layer was washed with aqueous sodium thiosulfate solution $5 \%(10 \mathrm{~mL})$, and the aqueous layer was extracted several times by dichloromethane $(15 \mathrm{~mL})$. The organic layers were combined and evaporated under reduced pressure. The support-bound nucleosid- $5^{\prime}$-yl phosphate was precipitated from a dichloromethane solution, by addition of an excess volume of cold diethyl ether $(150 \mathrm{~mL})$. The precipitate was filtered and washed with diethyl ether. The final product was recrystallized from ethyl alcohol absolute $(5 \mathrm{~mL})$ and dried under vacuum over $\mathrm{KOH}$ pellets. Compound $\mathbf{2 b}$ was obtained as a yellow solid $(0.14 \mathrm{~g}$, quantitative). $\delta_{\mathrm{H}}\left(\mathrm{D}_{2} \mathrm{O}, 300 \mathrm{MHz}\right) 8.44\left(\mathrm{~d}, J_{6-5}=7.5 \mathrm{~Hz}\right.$, $\left.1 \mathrm{H}, \mathrm{H}_{6}\right), 7.26\left(\mathrm{~d}, J_{5-6}=7.5 \mathrm{~Hz}, 1 \mathrm{H}, \mathrm{H}_{5}\right), 6.25\left(\mathrm{~s}, 1 \mathrm{H}, \mathrm{H}_{1^{\prime}}\right)$, $5.40\left(\mathrm{~s}, 1 \mathrm{H}, \mathrm{H}_{4^{\prime}}\right), 4.42-4.07\left(\mathrm{~m}, 4 \mathrm{H},\left(\mathrm{OCH}_{2} \alpha\right)_{\mathrm{PEG}} \mathrm{H}_{5^{\prime} \mathrm{a}} \mathrm{H}_{5^{\prime} \mathrm{b}}\right)$, $3.84-3.36\left(\mathrm{~m},\left(\mathrm{OCH}_{2}\right)_{\mathrm{PEG}} \mathrm{H}_{2^{\prime} \mathrm{a}}\right), 3.20\left(\mathrm{~m}, 1 \mathrm{H}, \mathrm{H}_{2^{\prime} \mathrm{b}}\right), 3.10(\mathrm{q}$, $\left.J=7.2 \mathrm{~Hz}, 6 \mathrm{H},\left(\mathrm{CH}_{3} \mathrm{CH}_{2}\right)_{3} \mathrm{NH}\right), 2.82-2.67$ (m, 4H, $\mathrm{CH}_{2 \text { succ }}$ ), $1.15\left(\mathrm{t}, J=7.2 \mathrm{~Hz}, 9 \mathrm{H},\left(\mathrm{CH}_{3} \mathrm{CH}_{2}\right)_{3} \mathrm{NH}\right) ; \delta_{\mathrm{C}}\left(\mathrm{D}_{2} \mathrm{O}, 75 \mathrm{MHz}\right)$ $174.6,174.5\left(2 \mathrm{~s}, \mathrm{C}=\mathrm{O}_{\text {succ }}\right), 162.6\left(\mathrm{~s}, \mathrm{C}_{4}\right), 156.6\left(\mathrm{~s}, \mathrm{C}_{2}\right), 146.3\left(\mathrm{~s}, \mathrm{C}_{6}\right)$, $97.6\left(\mathrm{~s}, \mathrm{C}_{5}\right), 88.1\left(\mathrm{~s}, \mathrm{C}_{1^{\prime}}\right), 86.2\left(\mathrm{~d}, J_{\mathrm{C}^{\prime}-\mathrm{P}}=8.4 \mathrm{~Hz}, \mathrm{C}_{4^{\prime}}\right), 69.6(\mathrm{~s}$, $\left.\left(\mathrm{OCH}_{2}\right)_{\mathrm{PEG}}\right), 68.4\left(\mathrm{~s},\left(\mathrm{OCH}_{2} \beta\right)_{\mathrm{PEG}}\right), 64.8\left(\mathrm{~s}, \mathrm{C}_{5^{\prime}}\right), 64.1$ (s, $\left.\left(\mathrm{OCH}_{2} \alpha\right)_{\mathrm{PEG}}\right),\left(\mathrm{s},\left(\mathrm{CH}_{3} \mathrm{CH}_{2}\right)_{3} \mathrm{NH}\right), 37.9\left(\mathrm{~s}, \mathrm{C}_{2^{\prime}}\right), 31.6,28.5$ (s, $\left.\mathrm{CH}_{2 \text { succ }}\right),\left(\mathrm{s},\left(\mathrm{CH}_{3} \mathrm{CH}_{2}\right)_{3} \mathrm{NH}\right) ; \delta_{\mathrm{P}}\left(\mathrm{D}_{2} \mathrm{O}, 121 \mathrm{MHz}\right) 0.72$ (s).

Acknowledgment. C.C. is grateful to the French Ministry of Education and Research (MENRT) for a Ph.D. grant, and the authors thank the "Centre National de la Recherche Scientifique" (CNRS) for funding and M. C. Bergogne for manuscript editing.

Supporting Information Available: Experimental procedures and NMR spectra. This material is available free of charge via the Internet at http://pubs.acs.org. 